\title{
New perspectives for cemented hydraulic fill with chemical technologies
}

\author{
Z Martic UGC BASF Global, Switzerland
}

J Gelson UGC BASF Asia Pacific, Australia

H Brás Lundin Mining, Portugal

Q Xu UGC BASF Global, Switzerland

W Brosko UGC BASF NAFTA, Canada

\begin{abstract}
Hydraulic fill (HF) made a breakthrough in the mining industry around the turn of the 20th century and by the 1950s, with the addition of cement, it became a major backfill technique that significantly changed mining operations and output. Cemented hydraulic fill (CHF), was a major step forward compared to the existing bulk backfill techniques of the day. Cemented hydraulic fill provided better continuity in the backfill production and placement, improved reliability of the backfilling process, increased backfill production and mine production in general, simpler scheduling processes and start-up operation. However, CHF started to lose favour to newer backfilling technologies, such as paste backfill due to a number of difficulties. These were high water content requirements (large amounts of water needed for transportation), loss of binder during drainage, presence of slimes in drained water, costly dewatering, barricade safety, and non-uniform properties of the placed fill. Recent studies done by BASF have shown that, with the help of admixtures, it is possible to improve the flowability and uniformity of the placed fill, stabilise the CHF against segregation in the pipelines, increase solids content and improve dewatering of the placed fill. Also admixtures can assist in retaining the binder particles within the fill and get a more reliable and uniform cemented fill.
\end{abstract}

This initial internal study identifies some of the major mechanisms behind the CHF behaviour and aims to provide a better understanding of rheological and in situ properties of cemented hydraulic fill material. It will be shown that by introducing a suitable new chemical technology the flowability and uniformity of the placed fill was greatly improved. Finally, an external case study from Neves Corvo Mine in Portugal is presented, along with the transitional steps from the laboratory investigation to the actual field application. It is clearly demonstrated, based on laboratory and in situ test results, that the mine's CHF, when treated with a suitable admixture, can be rheologically stabilised, and the placement improved. It is also shown that the in situ properties can be significantly improved, the solids content can be increased (close to that of paste backfill) and the water management requirements can be decreased, thus making CHF a more favourable backfilling technique.

\section{$1 \quad$ Introduction}

Historically, HF was the first continuous method of mine backfilling in the mining industry. It significantly changed the aspect of mine backfilling and mining in general. At first, the fill materials used to produce hydraulic fill included water and total (unclassified) tailings (in the 1880s), or tailing sands (in the 1880s). Later on, classified tailings (in the 1940s), with the addition of binder (in the 1950s) were used, the latter two representing consolidated hydraulic fill and CHF, respectively. While CHF had improved many aspects of the backfilling process, it also exhibited some challenges, including binder loss during drainage and a continued need for costly dewatering. Despite major improvements in equipment design and capacity, pressure monitoring and computer integrated systems, some difficulties in CHF operations still remain. Namely, maintaining critical transportation velocities along the entire length of pipeline, reliable drainage and dewatering conditions of the placed fill to reduce the risk of liquefaction and barricade failure. 
The mining industry in the 1970s and 1980s had begun to face new challenges, including the extraction of deep reserves and the recovery of highly stressed sill pillars. The requirements for the more rapid turn-around cycle times and high mine output called for newer and more efficient mine backfilling methods; the emergence of CPF. This new backfilling technique, CPF, has continued to expand globally as the major mining backfill method (Potvin et al. 2005). With more mines using CPF, the question arises about the future of CHF. This study demonstrates that, with new admixture technologies, the improved $\mathrm{CHF}$ can render lower operational costs compared to untreated $\mathrm{CHF}$, and, due to lower capital cost when compared to $\mathrm{CPF}$, it can be a more favourable option for smaller mines or mines with limited mine life and budget. The current aspects of CHF along with an actual mine case study using advanced chemical technologies, specifically developed for this type of fill, will now be discussed.

\section{General characteristics of cemented hydraulic fill}

In underground mining with backfill, the ore recovery operation depends on the stability of the surrounding backfill, governed by the backfill strength and exposure dimensions. The results of several studies show that binder type and content and fill density are essential factors affecting CHF stability and production associated costs. These often define if the proposed backfilling technique is sustainable. The CHF technique can be classified into two groups:

1. Cyclic backfilling, where rock conditions are relatively poor and a low ore dilution operation is required.

2. Delayed backfilling, where there are generally better rock mass conditions and efficient production is required.

In cyclic backfilling, often used in cut-and-fill operations, the CHF acts as a platform for the mining equipment. In delayed backfilling, CHF is often required to act as a free standing wall after being exposed during pillar recovery and where stope size plays a key role in determining the backfill strength properties. Also, sequencing should be carefully assessed in regard with detailed stope design and optimised net present value (Bawden 2010). The choice of the backfill system often depends on the cost and availability of the backfill constituents at a particular site.

The $\mathrm{CHF}$ technique includes hydraulic transportation of $\mathrm{CHF}$ through a reticulation system from the surface down to the underground stope using gravity as the driving force. Fill material is classified to facilitate the enhanced dewatering of the placed fill in the stope. To ensure good percolation properties in CHF, the finer fraction of mine tailings and sand is removed using hydro-cyclones, leaving mainly silty sands or sandy silts with negligible clay fraction. This concept has a strong impact on rheology of the fill and also on the in situ properties of placed and dewatered fill.

There are two major issues related to CHF:

1. It is important to know that the optimum backfill system is the one that helps achieve the maximum value for the entire mining operation, not necessarily the lowest capital cost or lowest cost of the placement operation. It has to be evaluated as a part of the mining operation in total rather than an isolated system (Bawden 2010).

2. The efficiency of the backfill method depends on how this can be executed without interfering with each of the various independent mining operations. In general, the improved efficiency, production and time gains, in combination with cost savings, can make CHF a key part of the mining operation.

\section{Theoretical and practical background}

CHF design is governed by the transportation criteria which depend on CHF material properties, such as particle size distribution (PSD), density and viscosity of CHF, also on the potential energy of the fill column and diameter of the pipe. Since CHF acts as a suspension, its stability is directly related to the diameter of 
the particles, particle density and shape, viscosity of the fluid, transportation velocity, and solids content (Cooke 2001; Pullum 2007).

The critical (deposition) velocity for solid-liquid mixture is the velocity below which the solids particles settle out and form a stationary bed (not a moving bed). Critical velocity is directly related to the settling velocity of the coarser (or denser) particles in heterogeneous slurry and the degree of turbulence in the flow. As a result, homogenous slurries have entirely different critical velocity characteristics than heterogeneous slurries. Liquid phase viscosity is a complex parameter that depends on viscosity of the fluid and colloidal chemistry of the finely dispersed particles, i.e. tailings fines and binder (Cooke 2001). These two phases form the carrier fluid and both can be successfully controlled by the use of admixtures (Martic et al. 2011).

The optimum water content that gives minimum porosity is determined at the intersection of the saturation curve and the minimum porosity line (Rankine et al. 2006). However, for transportation purposes, the fill requires the water content to be substantially greater than the optimum water content, compromising the in situ properties of CHF. For example, a hydraulic fill of $70 \mathrm{wt} \%$ solids and specific gravity of 2.9 has $55 \%$ volume of water (Grice 2008). Upon placement, a variable amount of water remains within the fill, tied up in the interstices, and the remainder either drains through the barricades or decants from the top of the fill (Rankine et al. 2006). Without a rational approach to CHF, it is believed that operators may take on unnecessary risks or run the CHF system inefficiently, which may result in production delays, lower strengths, etc.

Hydraulic conductivity, which describes the ease with which a fluid moves between solid particles, is another important characteristic of $\mathrm{CHF}$ that defines a flow of a fluid through the aggregates. Good hydraulic conductivity is required to ensure that the placed fill drains adequately so that the liquefaction risk is minimised. Hydraulic conductivity is not only mainly influenced by the amount of fines in CHF but also depends on porosity, shape of the particles, mineral composition, surface chemistry, viscosity of liquid phase and temperature. A hydraulic conductivity of at least $100 \mathrm{~mm} / \mathrm{h}$ is generally accepted as a critical value that ensures good drainage in CHF (Jofre et al. 2011). The same study shows that hydraulic conductivity varies with strata, with the top layer having the lowest hydraulic conductivity due to highest fines content as a result of segregation. Segregation depends on PSD, particle-particle interaction, surface characteristics and fluid properties (liquid phase) of CHF (Rankine et al. 2006; Cooke 2001), and increases with higher water content. Improving the distribution of fines within the fill will enhance top layer hydraulic conductivity, allowing free water to migrate via water channels to the top.

Figure 1 demonstrates the drainage process in untreated CHF (Figure 1(a)) and CHF treated with the admixture (Figure 1(b)). Water clarification on the top of the column of treated CHF indicates better dewatering, less slimes in the drained water and better fines retention within the fill.

Mechanical strength and stiffness are directly related to the relative density of the fill. When CHF is denser, the relative density and friction angle are higher, and thus the fill is more stable. In geotechnical engineering, there are several empirical correlations between relative density, Young's modulus, and friction angle of a granular soil (Sivakugan et al. 2006). 


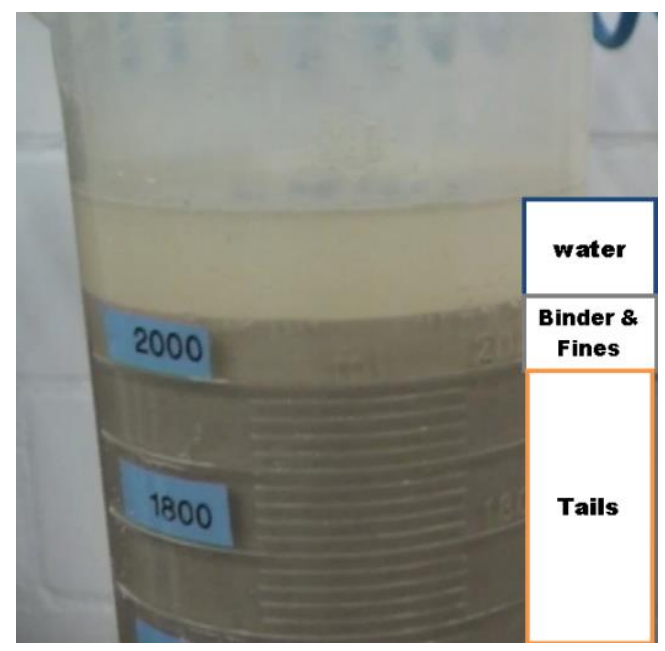

(a)

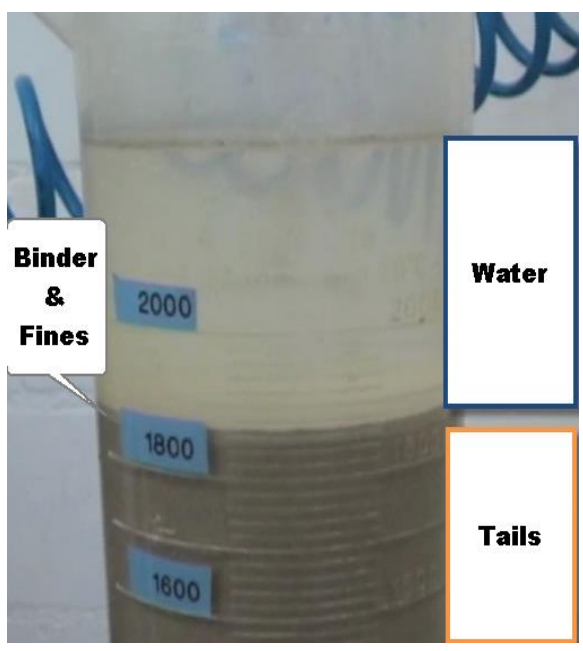

(b)

Figure 1 (a) CHF without admixture; and (b) CHF with MasterRoc MF 308

There are two major factors that determine the in situ strength of CHF:

1. Cohesion factor, defined by binder type, content and temperature.

2. Friction factor, defined by the shape of the grains.

\section{$4 \quad$ Chemicals in cemented hydraulic fill}

The first admixtures introduced to HF were flocculants. Some mines with HF (without cement) are still using flocculants to facilitate placement, but in CHF, the flocculants affect dewatering and the stability of placed fill by causing the binder particles to create flocs and block drainage channels. Admixtures can be especially beneficial to a CHF with unfavourable PSD and drainage characteristics, in which a significant amount of fines can remain mobile in the placed fill, and migrate to the liquid phase during the dewatering process. This causes layering or stratifying of the placed fill, as presented in Figure 2 . The consequence of such a process is a negative effect on the uniformity of the CHF.

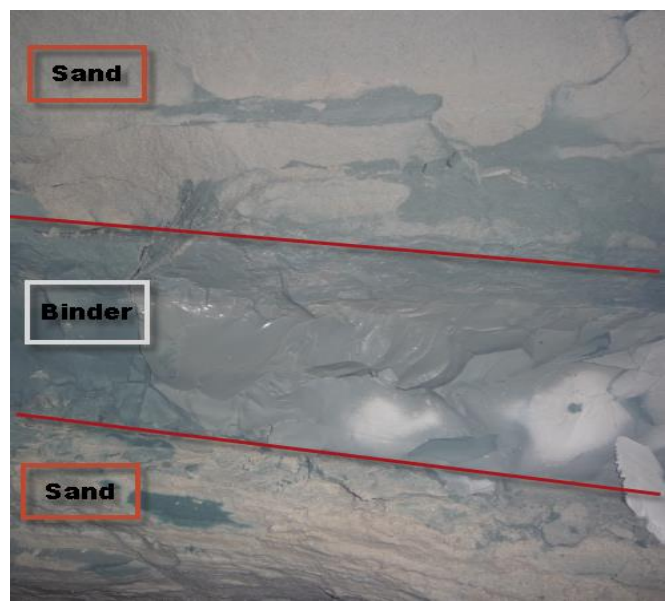

(a)

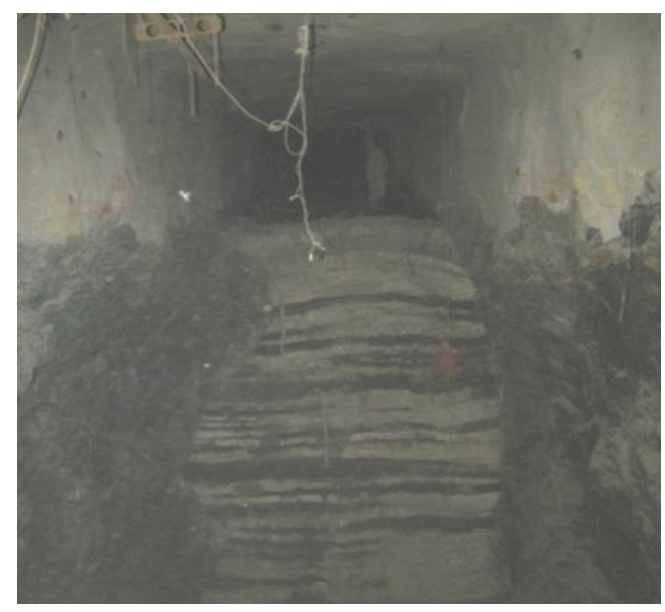

(b)

Figure 2 (a) binder layer identified within two sand layers; (b) stratified fill mass in a stope

The properties of the placed $\mathrm{CHF}$, including void ratio, hydraulic conductivity and unconfined compressive strength (UCS) are hence affected negatively. The variations in the UCS within the placed fill especially will have a negative effect on the degree of dilution during blasting next to the backfilled stope. In CHF, admixtures aim to provide rheological stability and desirable particle distribution of the larger aggregates in 
poorly classified tailings by keeping the fines within the matrix structure of the fill during the transportation of fresh CHF and during the dewatering phase of the placed fill.

Figure 3 illustrates how a suitable polymer can help evenly distribute the fines in the carrier fluid, so that the larger aggregates would not undergo extensive segregation under turbulent conditions, thereby providing better uniformity of the fill and better hydraulic conductivity of the layers. This advanced polymer technology can lower the amount of excess water in the placed fill, provide better flow properties of the fill, result in a higher uniformity and UCS. It also limits the amount of fines migration (slimes) and decreases the water quantity needed for transportation. Improved rheological properties and higher solids content can provide conditions for tight filling which could be otherwise challenging to achieve in conventional hydraulic fill without admixtures/chemicals. With improved strength properties of the placed fill, it is realistic to attain binder reduction and lower overall cost of the backfill operation.

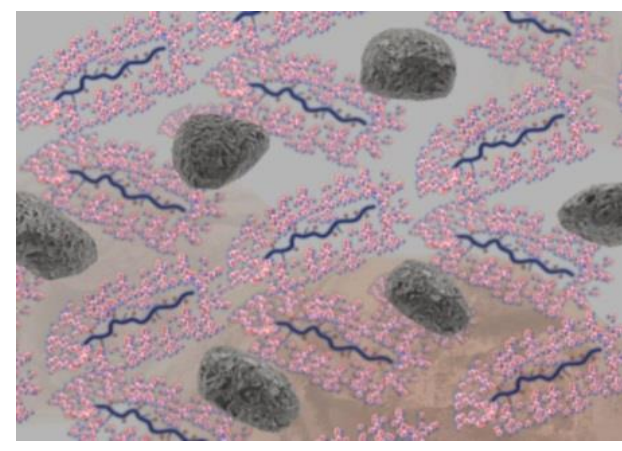

(a)

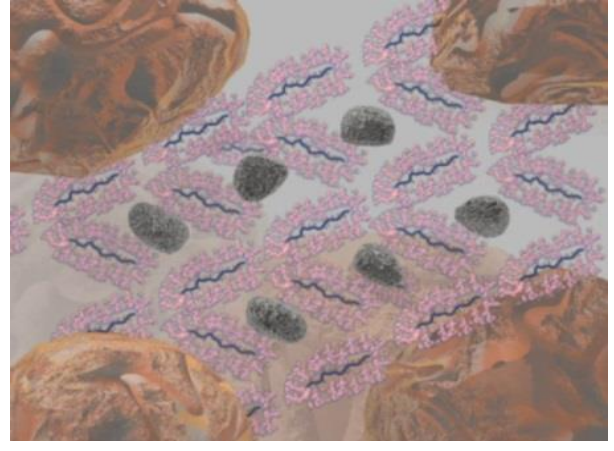

(b)

Figure 3 (a) polymer structure with built-in fines; (b) carrier fluid carrying larger particles

\section{$5 \quad$ Case study - Neves Corvo Mine in Portugal}

\subsection{Lab testing}

CHF consisted of sand, tailings, binder and water. The control CHF samples prepared in the lab had the same recipe as the mix in the mine: 77 wt\% solids, 3 wt\% binder, and 20 wt\% water. The solids consisted of $2.5 \mathrm{wt} \%$ tailings and $97.5 \mathrm{wt} \%$ sand. Tailings and sand properties are presented in Table 1. Particle size distribution of tailings and sand are shown in Figure 4. Table 2 shows the CHF samples containing various amounts of admixture that were tested in this study.

\section{Table 1 Material properties}

\begin{tabular}{lcc}
\hline Parameters & Tailings & Sand \\
\hline Moisture content $(\mathrm{wt} \%)$ & 71.4 & 2.1 \\
Specific gravity & 3.42 & 2.65 \\
Bulk density $\left(\mathrm{g} / \mathrm{cm}^{3}\right)$ & 1.22 & 1.61 \\
pH of mix with mine water & 5.52 & 3.67 \\
\hline
\end{tabular}

The main minerals in the tailings were pyrite, quartz and biotite, followed by a small amount of clay mineral illite. The sand contained mainly quartz and feldspar and some traces of biotite. The binder was Portland cement, blended with limestone and granulated blast furnace slag (its presence confirmed by the presence of Merwenite). Cement belongs to CEM 32.5 R class. Mineral composition of sand, tailings and binder are presented in Table 2. 
Table 2 X-ray diffraction analysis (ETH Zürich - Institut für Geochemie und Petrologie Diffraktometer D8 Advance, Bruker. Measurements semi-quantitative)

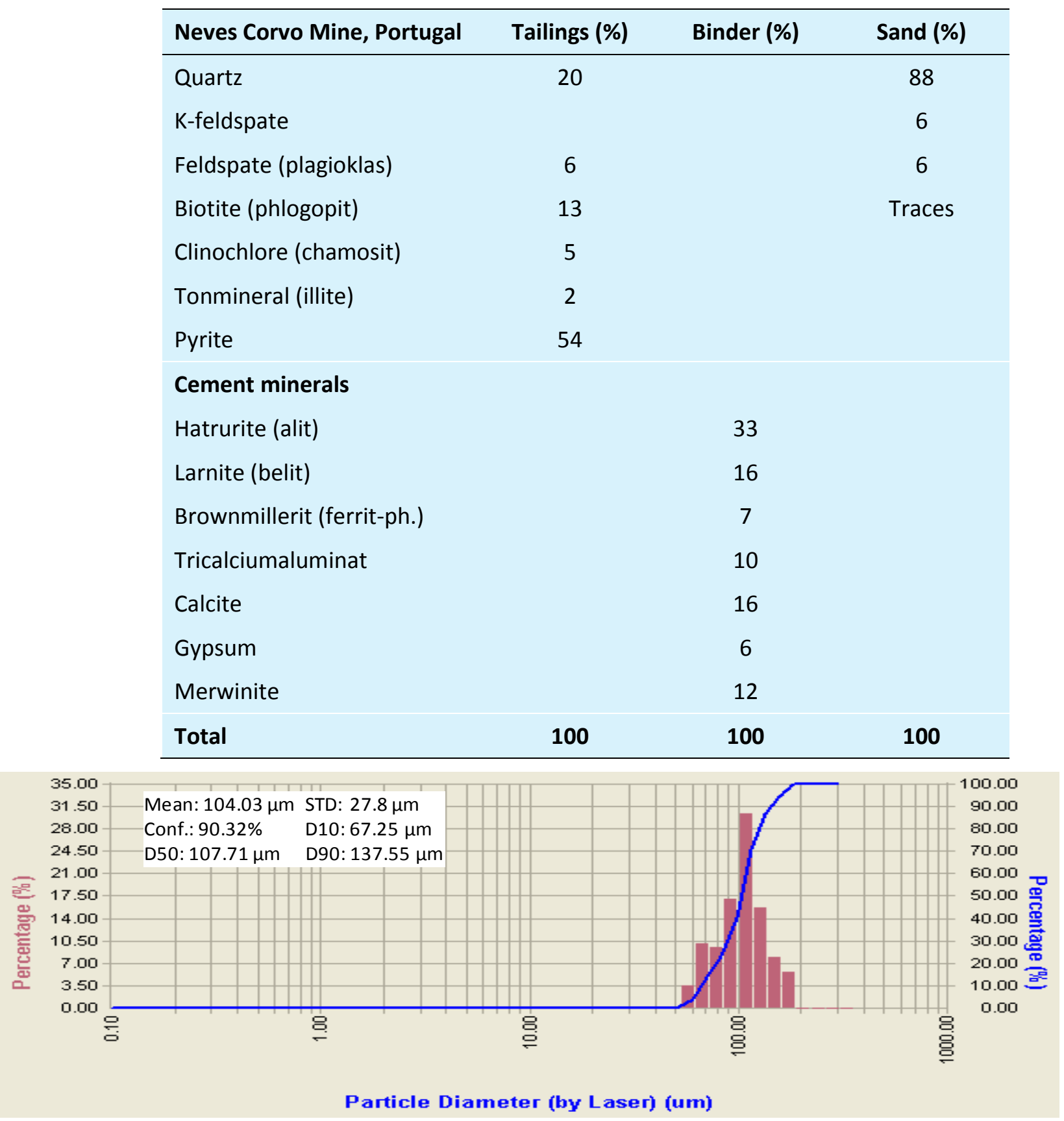

Figure 4 PSD of tailings from Neves Corvo Mine 


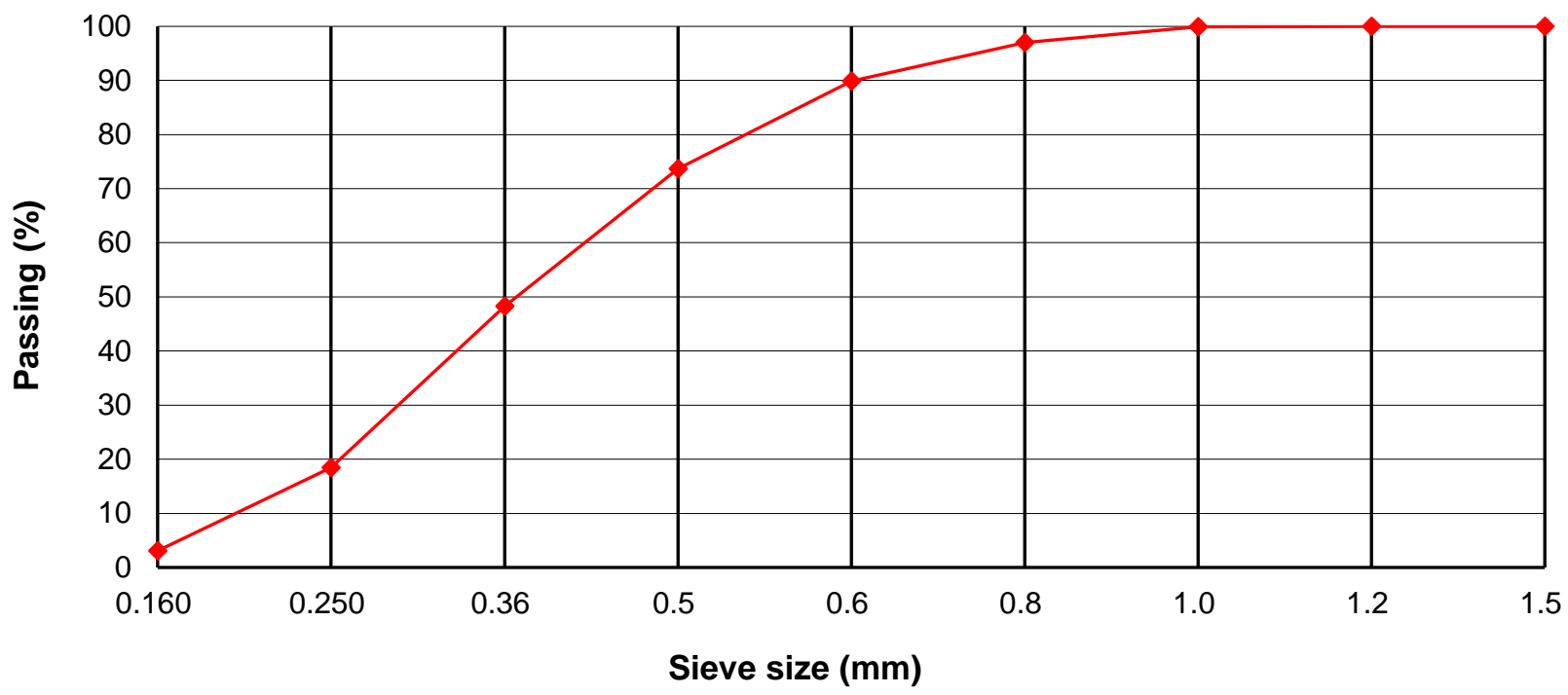

Figure 5 PSD of sand

Rheological measurements in the lab were done using the flow meter that was developed by the authors to evaluate flow properties of high segregating slurries, such as HF or CHF. This custom built flow meter, shown in Figure 6, was used to avoid influence of the settlement during flow measurements and also to bring the conditions of the lab testing closer to those in the field. This apparatus facilitates gravity flow without any pressure in the tank. During the test, the critical issue is the segregation of the coarser fraction and/or heaviest minerals during the measurements. The test results directly depend on the ability to keep all particles suspended in the tank before and during the measurement.
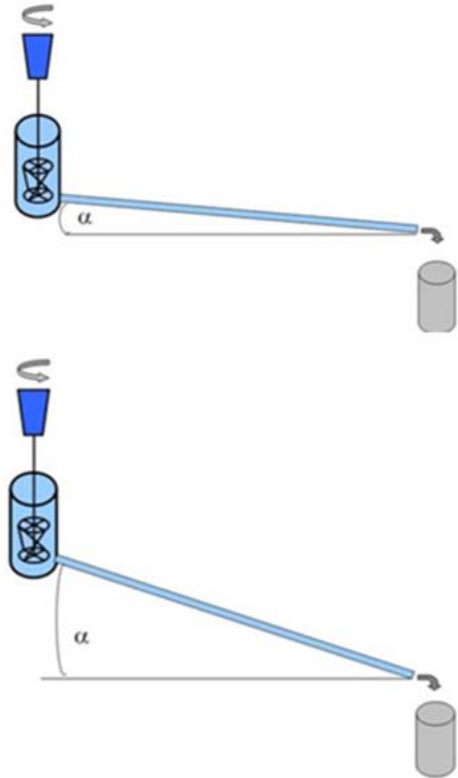

Figure 6 Flow meter

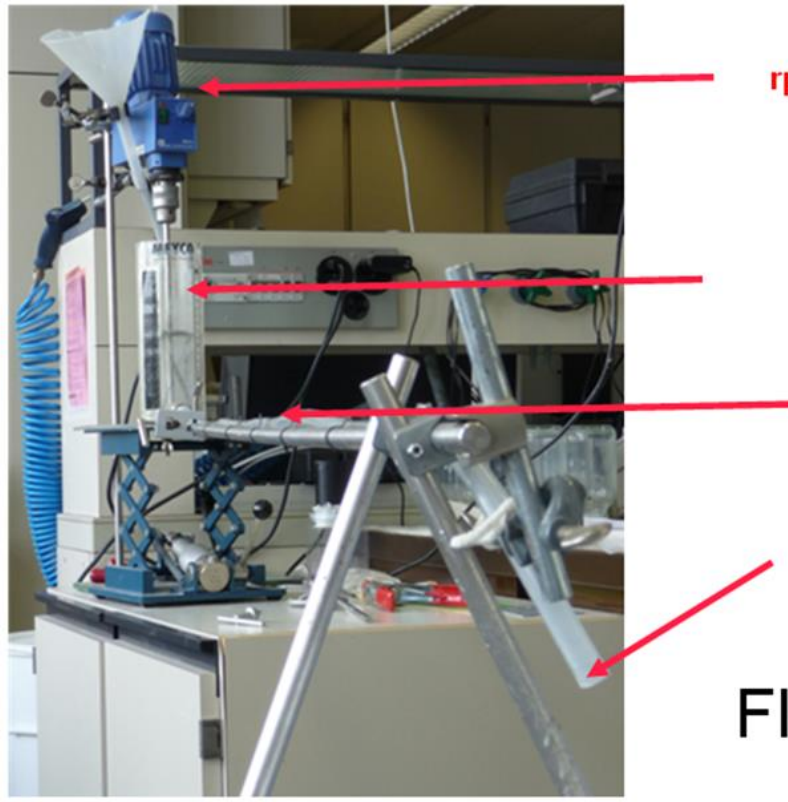

rpm measurements

Const volume

Variable slope of pipes

Flow rate 
Table 3 Testing matrix and mix design

\begin{tabular}{cccc|c|c|}
\hline Test no. & Solids (\%) & Binder content (\%) & Admixture type & Dosage (mL/t) & Slope angle $\left(^{\circ}\right)$ \\
\hline B-1 & 77 & 3 & Control & 0 & 13.72 \\
B-2 & 79 & 3 & Control & 0 & 13.72 \\
B-3 & 79 & 3 & MMF 308 & 350 & 13.72 \\
B-4 & 79 & 3 & MMF 501 \& 308 & $100+350$ & 13.72 \\
B-5 & 79 & 3 & MMF 303 & 600 & 13.72 \\
B-6 & 79 & 3 & MMF 701 & 500 & 13.72 \\
\hline B-7 & 79 & 3 & MMF 701\& 308 & $300+200$ & 13.72 \\
\hline
\end{tabular}

Figure 7 illustrates the effect of various admixtures on flow in the pipeline. Similar trends were recorded in the large scale testing at the mine. Flow meter test results suggest that admixture MMF 308 in combination with MMF 701 or MMF 501 gave the best effect on flow characteristics. The flow time was decreased in the CHF by 9.21 and $11.84 \%$ respectively as compared to the lower solids content control CHF. Admixture MMF 701 had best flow time but a higher settlement rate compared to the other two proposed mix designs with MMF 308 and MMF 701.

\section{Flow time curve}

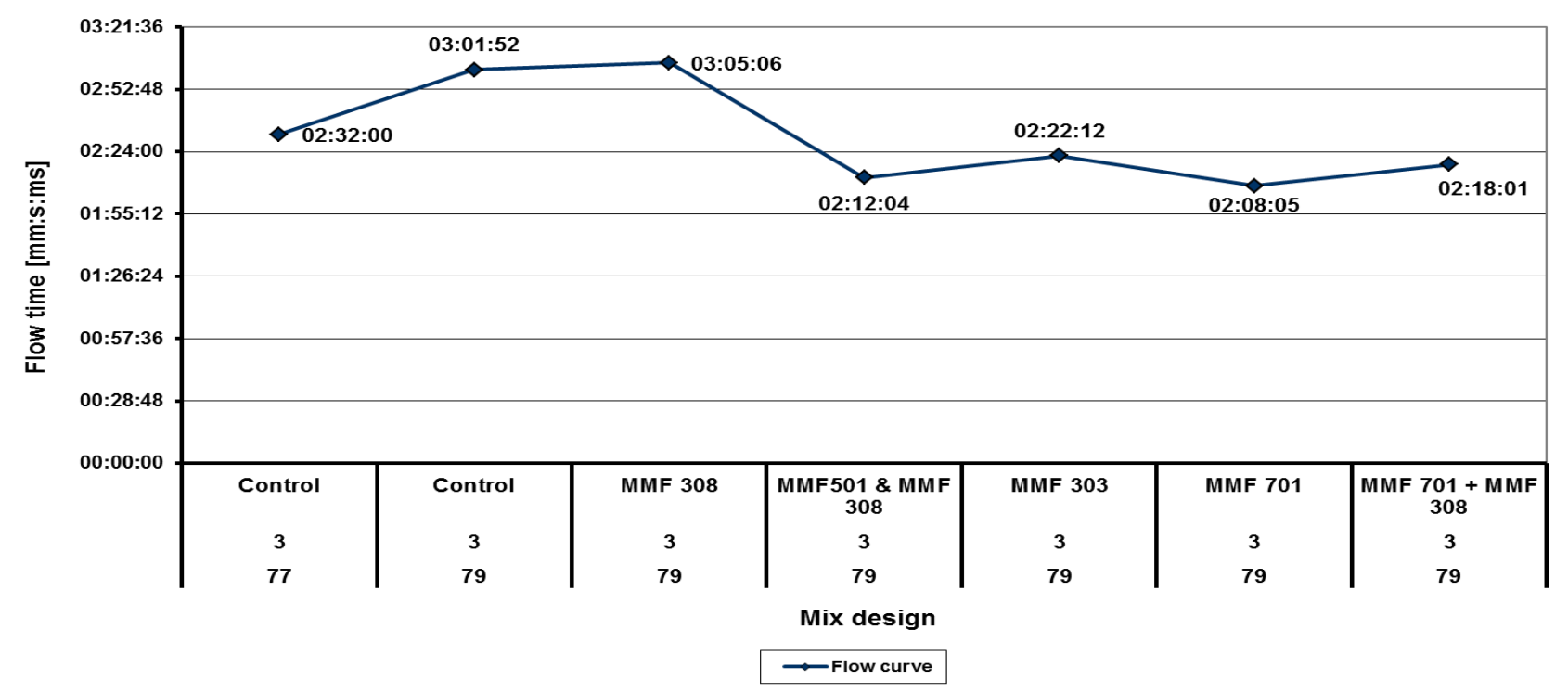

Figure 7 Flow meter results for CHF with various admixtures

Additional findings include:

- Solids content has significant influence on flow properties, an increase in solids content from 77 to $79 \mathrm{wt} \%$ increases the travel time of the control CHF. This 'travel or flow time' increased by $19.7 \%$ for the control when solids content was increased by $2 \%$.

- Viscosity-modifying admixtures (stand-alone or in a combination with other types of admixtures) significantly changed the rheological properties of the fill. Comparing results of fill with admixture at $79 \%$ solids to control at $77 \%$ it can be seen that admixture MMF 303 has a $5.26 \%$ shorter traveling time as compared to the control. Combination of MMF 308 \& MMF 501, a $11.84 \%$ shorter travelling time, and admixture MMF 308 \& MMF 701, a 9.21\% shorter travelling time. 
- From filmed material during experiments it was identified that the flow regime changes from sliding/stationary bed to full flow. Significantly improved stability of the fill (in terms of segregation) in a horizontal line can be observed and related to faster flow with admixtures.

- UCS properties of CHF changed with admixture addition, depending on the type of admixture (Figure 8). MMF 308 alone didn't have any benefit to UCS in this study, MMF 303 had a $44.83 \%$ higher 28 day UCS as compared to control at 77\% solids. Admixtures MMF 308 \& MMF 701 had a $55.17 \%$ higher 28 day UCS as compared to control. UCS of CHF with admixtures MMF 308 \& 701 at $79 \mathrm{wt} \%$ is greater than UCS of the control CHF at $77 \mathrm{wt} \%$ and $79 \mathrm{wt} \%$.

- The combination of admixtures MMF 701 and MMF 308 had very good results at all ages in regard to UCS and flow properties. This mix design was recommended for large scale testing at the mine.

- Based on lab results, the recommendation for field tests included testing CHF with different mix designs in the mine with admixtures MMF 308, and a combination of MMF 308 with MMF 701 at various dosage rates to get the correlation between dosage rates and rheological properties of the fill in order to find the best possible and most cost effective solution for the mine.

\section{UCS results}

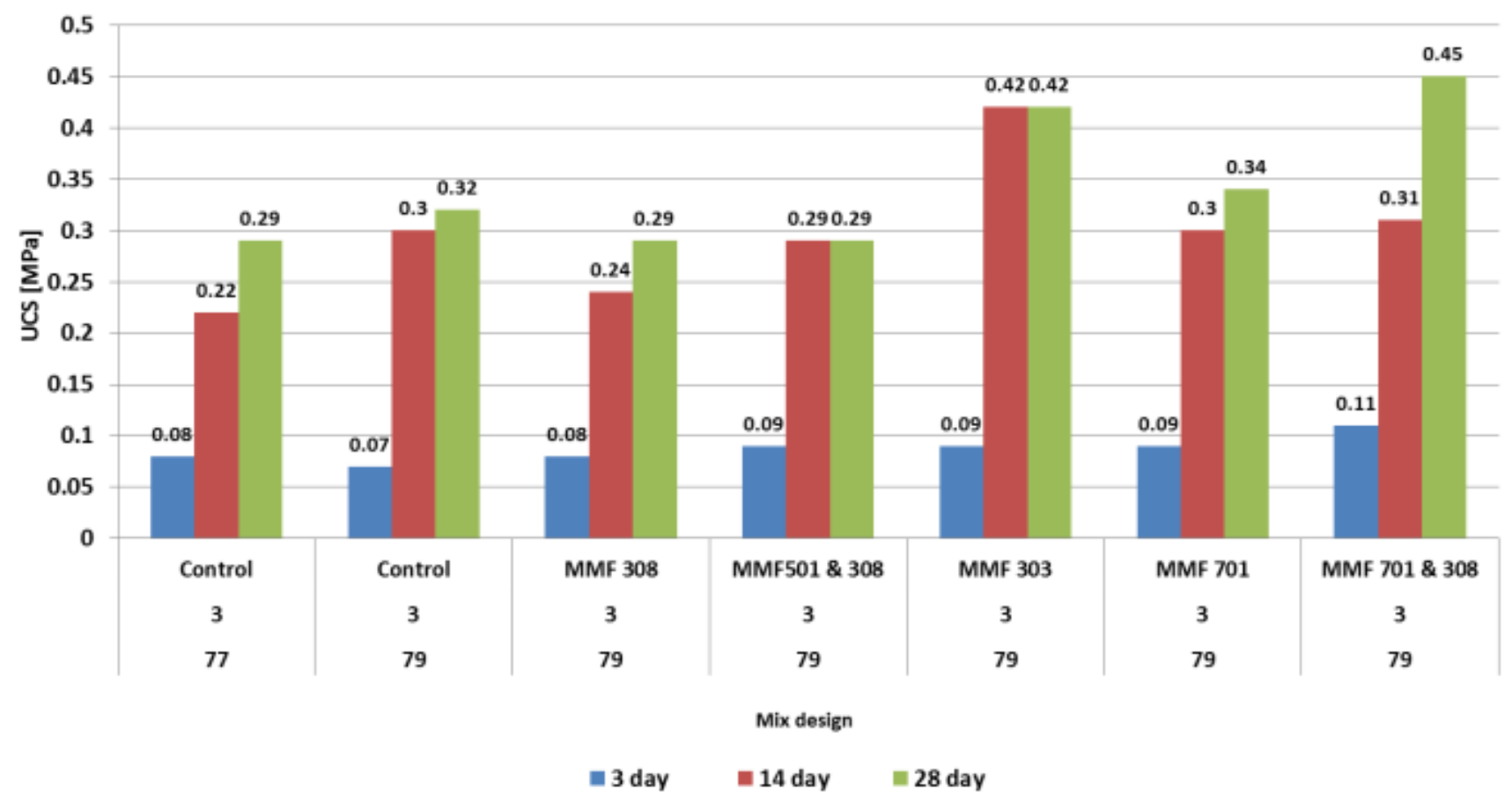

Figure 8 UCS results for CHF with various admixture technologies

\subsection{Field testing}

The purpose of the final mine site testing with the BASF admixtures from 16/10/2012 to 21/11/2012 was to evaluate benefits with regards to safety and productivity of the hydraulic fill using admixtures. The behaviour of the fill in different lines at different locations was explored to quantify the benefits. Productivity of the plant, based on feed rate was measured and compared to historical data. The table below represents the fill rates for both fill lines until the end of the test $(21 / 11 / 2012)$. During the test, the maximum feed $\left(\mathrm{m}^{3} / \mathrm{h}\right.$ ) was achieved; it represented an increase of $10.6 \mathrm{~m}^{3} / \mathrm{h}$ (from $119-128.4 \mathrm{~m}^{3} / \mathrm{h}$ ) compared to historical data. It was determined by the mine that the underground fill rates were increased by $7.9 \%$ overall. 
Table 4 Plant productivity review - without and with admixture

\begin{tabular}{lccccccc}
\hline & $\begin{array}{c}\text { Volume } \\
\left(\mathbf{m}^{\mathbf{3}} \mathbf{)}\right.\end{array}$ & $\begin{array}{c}\text { Worked } \\
\text { hours }\end{array}$ & $\begin{array}{c}\text { Feed rate } \\
\left(\mathbf{m}^{3} \mathbf{h} \mathbf{h}\right)\end{array}$ & $\begin{array}{c}\text { Volume } \\
\left(\mathbf{m}^{\mathbf{3}}\right)\end{array}$ & $\begin{array}{c}\text { Worked } \\
\text { hours }\end{array}$ & $\begin{array}{c}\text { Feed rate } \\
\left(\mathbf{m}^{\mathbf{3}} \mathbf{/ h}\right)\end{array}$ & $\begin{array}{c}\text { Line 1 and 2 } \\
\text { average feed } \\
\text { rate }\left(\mathbf{m}^{3} / \mathbf{h}\right)\end{array}$ \\
\hline January & 21,292 & 183 & 116.3 & 25,929 & 216 & 120.0 & \\
February & 19,269 & 170 & 113.3 & 21,529 & 188 & 114.5 & \\
March & 12,395 & 113 & 109.7 & 19,736 & 170 & 116.1 & \\
April & 24,501 & 181 & 135.4 & 22,484 & 220 & 102.2 & \\
May & 18,872 & 160 & 118.0 & 22,029 & 189 & 116.6 & \\
June & 15,158 & 121 & 125.3 & 18,116 & 168 & 107.8 & $\mathbf{1 1 7 . 8}$ \\
July & 16,989 & 134 & 126.8 & 20,257 & 173 & 117.1 & \\
August & 16,631 & 143 & 116.3 & 23,995 & 207 & 115.9 & \\
September & 16,235 & 128 & 126.8 & 20,671 & 169 & 122.3 & \\
October & 14,985 & 118 & 127.0 & 26,259 & 216 & 121.6 & \\
November & 13,760 & 107 & 128.6 & 19,818 & 161 & 123.1 & \\
Test BASF & 20,365 & 155 & 131.4 & 32,487 & 259 & 125.4 & $\mathbf{1 2 8 . 4}$ \\
\hline
\end{tabular}

These increased flow rates in the two pipelines were equally achieved for stopes which were considered difficult to fill due to long horizontal lengths of the pipelines. In some particular stopes in these two orebodies higher water content (historically) needed to provide flowability, was not required when admixtures were used. Production was more reliable even for more challenging lines where normally more water was added. It was found that the fill achieved much higher solids content as compared to fill without admixtures and also retained good flow characteristics, reducing the risk of production interruptions and blockages.

Cylinders were taken at the barricade, but as these could be variable and not representative samples from the general stope during filling, penetration tests were also done to evaluate in situ strengths of the placed fill. Results from UCS and penetration tests are presented below. The average results, even with high scattering of data show that the average UCS when using admixtures is $71.5 \mathrm{kPa}$ and without $64 \mathrm{kPa}$. This is a $10 \%$ higher value (line diagrams). The mine utilised a penetration test to determine comparative strength development of the fill and the results are presented in Figure 9.

The stopes filled using admixture had a more consistent behaviour, and a higher average in situ UCS. The two stopes below $450 \mathrm{kPa}$, Z7204B09 and C6577B06, caused sidewall dilution around 6\% in Z7204B11 and C6577B10. Looking at average in situ UCS results, stopes filled with admixture had $27 \%$ more strength than normal fill. 


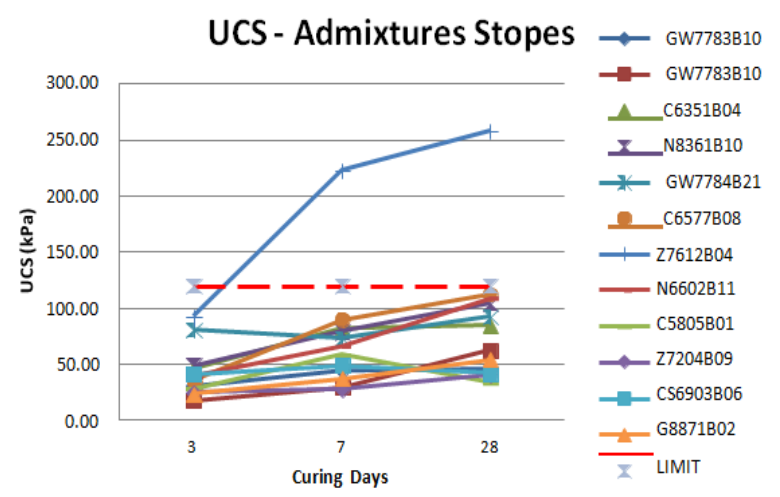

In Situ UCS - Admixtures Stopes

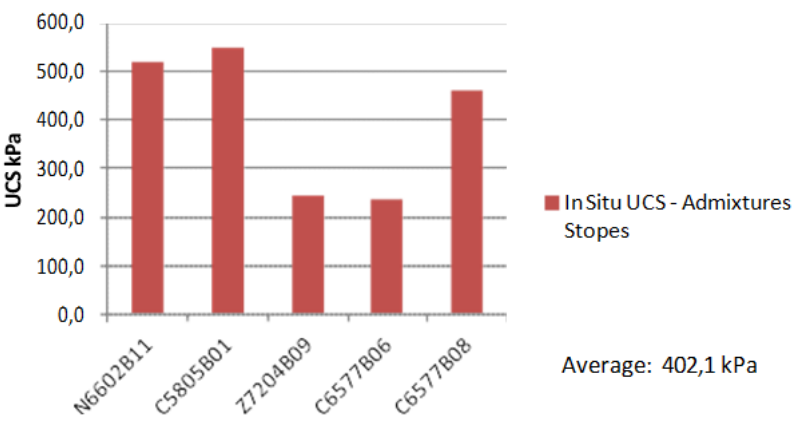

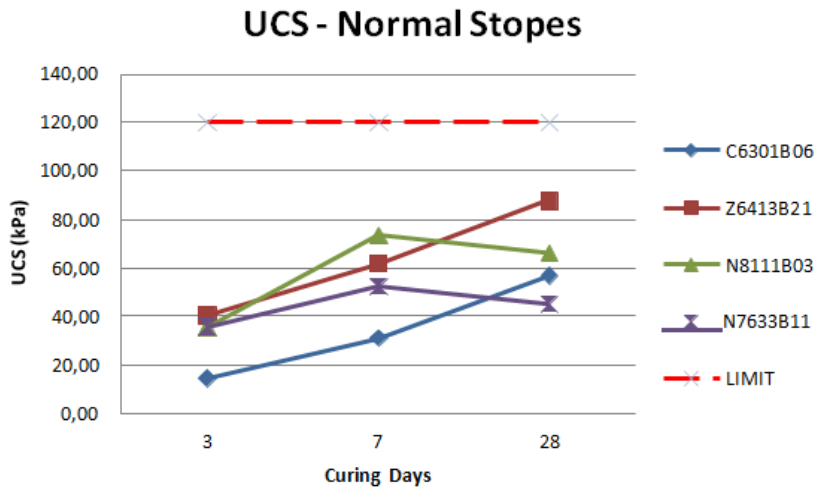

In Situ UCS - Normal Stopes

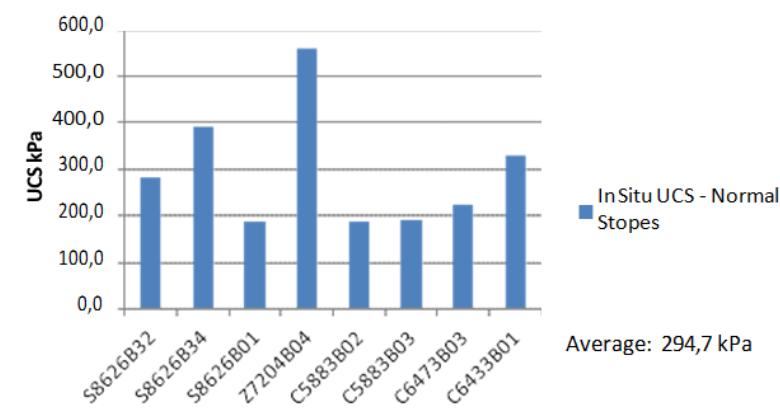

Figure 9 UCS test results on CHF with various admixtures

Analysing the dilution in the stopes as reported by the mine (Tables 5 and 6), it was apparent that the sidewall dilution was reduced using admixtures. Average side wall dilution (SH) was reduced by $17 \%$ as compared to reference stopes without admixtures. The apparent reduction of sidewall dilution would have an impact on:

1. Ore grade.

2. Less volume to backfill.

3. Less haulage and skip occupation with hydraulic fill.

4. Less hydraulic fill in ore processing.

5. Overall cost reduction of mining, filling, hauling and processing.

Obviously the properties of CHF have a huge impact on sidewall dilution; expected increase in UCS and reduced dilution. The analysis of all results from the mine testing can be summarised as follows:

1. Higher plant through put of $10.6 \mathrm{~m}^{3} / \mathrm{h}$. Multiplying the $10.6 \mathrm{~m}^{3} / \mathrm{h}$ by monthly worked hours in the two lines $(168 \mathrm{~h})$, it represents an increment of $3,562 \mathrm{~m}^{3} /$ month. At the end of the year this means an additional $42,739 \mathrm{~m}^{3}$, the equivalent to a full good month of hydraulic fill operation.

2. Lower average sidewall dilution reported by the mine means less diluted ore grade, less volume to re-fill and less haulage and skip occupation with hydraulic fill. Continuous use of admixture will provide more statistical data.

3. Less water usage, a reduction on average of $13 \%$, this means that solids increased from 77 to $80 \%$.

4. Less shrinkage effect, and by increasing the through put of the plant, stope filling times are reduced.

5. More homogeneous mixture, hence less segregation, assisting fill flow rate due to lower flow resistance in the pipe. Flow moves towards paste type mode, as the pipes are totally filled. No safety issues with the wooden fences were seen during the test. 
6. Mine team reported better control and smoother running of the filling operation.

7. Better and smoother flowability. No pulsation on the end of the fill pipes was reported from the underground mine team. Video footage confirms this.

8. During an industrial test, torque was measured by means of current amperage. Torque in the mixers remained constant even at higher solids content confirming the effectiveness of the admixture.

9. Tight filling of the stopes should be more easily achieved due to better rheology of the fill and the higher solids content resulting in less shrinkage.

10.Workers were able to walk over the fill after $30 \mathrm{~min}$. This timing is crucial, due to the need to build the designed wooden fence. This demonstrates improved dewatering capabilities of the fill with admixtures compared to the fill without. This qualitative remark from the underground mine team was based on their daily experience over many years.

11.During one stage of the industrial test, a blockage occurred and leakage was identified as the cause. The leakages happened in areas already known as critical, and were caused by high wear and high pressure in that section of the pipe. Unclogging the horizontal pipelines was improved significantly according to the mine team; the sections of eighth or ninth pipes could be cleaned in one go, instead of the usual four or five sections for similar cases in the same location. With this experience it can be said that even at higher densities of fill, safety is improved in the case of blockages.

Table 5 Dilution

\begin{tabular}{ccccccc}
\hline Face code & $\begin{array}{c}\text { Original grade } \\
(\%)\end{array}$ & $\begin{array}{c}\text { Diluted grade } \\
(\%)\end{array}$ & Rock XN & Floor FH & Sidewall SH & $\begin{array}{c}\text { Total dilution } \\
\text { (\%) }\end{array}$ \\
\hline C6577B06 & 7.41 & 7.10 & 0.00 & 0.32 & $\mathbf{4 . 0 2}$ & 4.3 \\
C6577B07 & 4.69 & 4.10 & 0.00 & 1.72 & $\mathbf{1 2 . 6 7}$ & 14.4 \\
G8821B04 & 3.07 & 2.44 & 16.11 & 0.24 & $\mathbf{9 . 4 3}$ & 25.8 \\
GW7784B & 10.69 & 9.76 & 4.31 & 0.68 & $\mathbf{4 . 5 7}$ & 9.6 \\
Z7204B06 & 12.19 & 11.50 & 0.00 & 1.54 & $\mathbf{4 . 4 3}$ & 6.0 \\
Z7204B07 & 12.06 & 11.50 & 0.00 & 1.65 & $\mathbf{3 . 2 2}$ & 4.9 \\
Z7204B13 & 2.98 & 2.78 & 0.00 & 2.82 & $\mathbf{4 . 2 1}$ & 7.0 \\
GW7783B05 & 8.26 & 7.35 & 8.0. & 0.0 & $\mathbf{2 . 7 0}$ & 11.0 \\
GW7783B14 & 7.80 & 6.35 & 14.0. & 0.0 & $\mathbf{4 . 5 8}$ & 18.6 \\
GW7784B23 & 6.97 & 6.71 & 0.0. & 0.0 & $\mathbf{3 . 7 0}$ & 3.7 \\
N6602B13 & 1.65 & 1.57 & 0.0. & 2.0 & $\mathbf{2 . 7 0}$ & 5.1 \\
N8003B04 & 1.98 & 1.85 & 0,00 & 0.0 & $\mathbf{6 . 3 3}$ & 6.3 \\
C5805B02 & 1.95 & 1.87 & 2.23 & 0.0 & $\mathbf{1 . 7 6}$ & 4.0 \\
C6577B10 & 10.55 & 9.66 & 1.54 & 0.73 & $\mathbf{6 . 1 8}$ & 8.5 \\
Z7612B06 & 1,76 & 1,66 & 0.00 & 0.0 & $\mathbf{5 . 4 0}$ & 5.4 \\
Z7204B11 & 2.09 & 1.88 & 0,00 & 4.02 & $\mathbf{6 . 0 0}$ & 10.0 \\
G8871B04 & 4.91 & 4.46 & 7.57 & 0.26 & $\mathbf{1 . 3 4}$ & 9.2 \\
\hline
\end{tabular}


Table 6 Dilution without and with admixtures

\begin{tabular}{cccccc}
\hline \multicolumn{3}{c}{ Without admixtures } & \multicolumn{3}{c}{ With admixtures } \\
& Tonnes & $\%$ & & Tonnes & $\%$ \\
\hline Total ore & $83,383.1$ & & Total ore & $37,497.1$ \\
Total SH & $4,924.8$ & $\mathbf{5 . 2 9}$ & Total SH & $1,760.1$ & $\mathbf{4 . 3 7}$ \\
Total FH & 830.9 & 0.89 & Total FH & 339.6 & 0.84 \\
Total XN & $4,004.0$ & 4.30 & Total XN & 674.0 & 1.67 \\
Total dilution & $9,759.7$ & 10.48 & Total dilution & $2,773.7$ & 6.89 \\
Floor FH & $93,142.8$ & & Floor FH & $40,270.8$ & \\
\hline
\end{tabular}

\section{Conclusions}

Hydraulic fill brought a big improvement to the mining industry when it was introduced, and for years remained the most important and common backfill operation. The simplicity of setup made it a widely spread technique in the mining industry in most countries worldwide. Advantages were numerous but mostly related to flexibility of the operation, the number of people involved and filling rates. Material used for backfill was already available onsite and could be deposited underground than on the surface. Disadvantages of CHF are related to dewatering and water amounts in general, higher liquefaction risk, stratification and/or poor uniformity of the fill, and high operating costs. Water management, slimes, and the operating cost of hydraulic backfill were no longer acceptable in modern mining when compared to newer paste technologies.

The laboratory tests to determine the effects of admixtures on CHF were effectively confirmed by the onsite mine tests. The mine site case study with Neves Corvo mine showed clearly that CHF properties can be further improved in respect to:

- Higher solids content close to light paste conditions, and consistency of the fill close to 'light paste'.

- Better flow properties and lower blockage risk.

- Better UCS properties of the fill, especially measured with a penetrometer in the exposed stope.

- Potential for binder reduction.

- Improved in situ properties measured via reduced dilution in the stopes.

- Higher filling rates and capacity of existing plant setup, potential one month production gain per year.

- Lower water consumption and lower dewatering/desliming cost.

With recently available results from several field tests, one presented here and some ongoing, it can be concluded that the CHF operation can be significantly improved and that CHF can become a cost-effective solution which can respond to challenging requirements in many mines.

CHF could also become a more attractive backfill solution for smaller mines or mines with limited life as capital cost of a CHF plant compared to a paste plant, as well as technical requirements to operate it are much less. With improved flow and in situ performances of the fill and with a better cost structure, CHF with admixtures can definitely find a place in mining in the future.

Properties of the fill could be controlled via admixture combination and dosage variation to actively respond to the fluctuation of material feed or different technical requirements such as difficult lines, insufficient head, segregation and high friction in lines. 
An improved cost structure can be seen from potential binder reduction, lower water consumption, lower energy consumption, higher filling rates, lower labour cost, and lower dewatering cost. The company backfill group will continue the research program in $\mathrm{CHF}$ as we can definitely see potential for further improvement.

\section{Acknowledgement}

We would like to say thanks to Lundin Mining Company, who provided us with great support during the testing and have an understanding in supporting this pioneering project. We also thank them for providing the data from the testing and allowing them to publish and share it with the mining community. My personal thanks to Mr José Lobato, mine manager, and Mr Rodolfo Machado, chief engineer of the geotechnical department, for all their support and efforts in scheduling and planning day-to-day activities and production during the test. I would personally like to thank Mr Hugo Brás for submitting data, analysing it, making valuable comments, and leading the surface and underground crew. Also, without the help of backfill superintendent $\mathrm{Mr}$ João Pires and his vast experience it would not have been possible to drive this trial in a safe and efficient manner and we thank him for that.

\section{References}

Bawden, WF 2010, Cemented paste backfill systems \& the mining cycle, 13th International Seminar on Paste and Thickened Tailings Workshop, course notes, Toronto, Canada.

Cooke, R 2001, 'Design procedure for hydraulic backfill distribution systems', Journal of the South African Institute of Mining and Metallurgy, vol. 101, no. 2, pp. 97-102.

Grice, AG 1998, 'Underground mining with backfill', Proceedings of the 2nd Annual Summit - Mine Tailings Disposal Systems, pp. 234-9.

Jofre, J, Grice, AG, Bamford, W \& Styles, J 2011, 'Variability reduction for hydraulic fill conductivity measured in laboratory', in HJ Ilgner (ed.), Proceedings of the 10th International Conference on Mining with Backfill, The Southern African Institute of Mining and Metallurgy, Johannesburg, pp. 305-314.

Martic, Z, Gelson, J, Champa, J \& Knight, B 2011, 'Admixture in backfill applications for cost and performance benefits', in RJ Jewell \& AB Fourie (eds), Proceedings of the 14th International Seminar on Paste and Thickened Tailings, Australian Centre for Geomechanics, Perth, Western Australia, pp. 523-37.

Potvin, Y, Thomas, EG \& Fourie, AB (eds) 2005, Handbook on Mine Fill, Australian Centre for Geomechanics, Perth, Western Australia.

Pullum, L 2007, 'Pipelining tailings, pastes and backfill', in AB Fourie \& RJ Jewell (eds), Proceedings of the Tenth International Seminar on Paste and Thickened Tailings, Australian Centre for Geomechanics, Perth, pp. 113-27.

Rankine KJ, Sivakugan, N \& Cowling, R 2006, 'Emplaced geotechnical characteristics of hydraulic fills in number of Australian mines', Geotechnical and Geological Engineering, vol. 24, no. 1, pp. 1-14.

Sivakugan, N, Rankine, RM, Rankine, KJ \& Rankine, KS 2006, 'Geotechnical considerations in mine backfilling in Australia', Journal of Cleaner Production, vol. 14, no. 12, pp. 1168-75. 